ARTÍCULO

\title{
“Peronización” y "desperonización” de la Universidad Obrera Nacional en Argentina
}

\author{
Álvaro Sebastián Koc Muñoz' (1D
}

\section{RESUMEN}

El presente trabajo tiene por finalidad analizar el proceso de "peronización" y "desperonización" de la Universidad Obrera Nacional en el periodo comprendido entre 1953 y 1956. Presentaremos - en principio - las características particulares del proceso de "peronización" de la referida institución, en el marco de un intento general por parte del gobierno peronista de "politizar" al conjunto del sistema educativo. Seguidamente, daremos cuenta del proceso de "desperonización” de esta institución - abierto a partir del golpe de Estado a Perón, el 16 de septiembre de 1955 - a través del cual los estudiantes y las nuevas autoridades interventoras de casa de estudios desmantelaron el aparato simbólico montado por el peronismo durante sus dos primeros años de funcionamiento bajo el gobierno presidido por Perón (1953-1955). Para realizar este estudio, relevaremos diversas fuentes documentales de carácter institucional y oficial, e información proveniente de entrevistas a ex estudiantes de la institución.

\section{PALABRAS CLAVE}

universidad; obrera; peronismo; peronización; desperonización.

'Instituto de Investigaciones en Humanidades y Ciencias Sociales, Consejo Nacional de Investigaciones Científicas y Técnicas de Argentina, Universidad Nacional de La Plata, Buenos Aires, Argentina. 


\title{
"PERONIZATION" AND "DEPERONIZATION" OF THE UNIVERSIDAD OBRERA NACIONAL IN ARGENTINA
}

\begin{abstract}
The purpose of this paper is to analyze the process of "peronization" and "deperonization" of Universidad Obrera Nacional between 1953 and 1956. We will present - in principle - the characteristics of the process of "peronization" of the referred institution, within the framework of a general attempt by the Peronist government to "politicize" the entire educational system. Next, we will approach the process of "deperonization" of this institution - open from the coup d'État to Perón, on September 16, 1955 - through which students and the new authorities involved in the house of studies dismantled the symbolic apparatus mounted by Peronism during its first two years of operation, under the government chaired by Perón (1953-1955). To carry out this study, we will review various documentary sources of an institutional and official nature, and information from interviews with former students of the institution.
\end{abstract}

KEYWORDS

university; worker; peronism; peronization; deperonization.

\section{“PERONIZAÇÃO” E “DESPERONIZAÇÃO” DA UNIVERSIDADE OBRERA NACIONAL NA ARGENTINA}

RESUMO

O objetivo deste trabalho é analisar o processo de "peronização" e "desperonização" da Universidad Obrera Nacional entre 1953 e 1956. Apresentaremos, em princípio, as características do processo de "peronização" da referida instituição, no âmbito de uma tentativa geral do governo peronista de "politizar" todo o sistema educacional. A seguir, descreveremos o processo de "desperonização" dessa instituição — aberto do golpe de Estado a Perón, em 16 de setembro de 1955 - por meio do qual os estudantes e as novas autoridades envolvidas na casa de estudos desmontaram o aparato simbólico montado pelo peronismo durante seus primeiros dois anos de operação sob o governo presidido por Perón (1953-1955). Para a realização deste estudo, revisaremos diversas fontes documentais de natureza institucional e oficial, além de informações de entrevistas com ex-alunos da instituição.

PALAVRAS-CHAVE

universidade; trabalhador; peronismo; peronização; desperonização. 


\section{INTRODUCCIÓN}

Desde su aparición en la vida política argentina a mediados de los años 40 , el peronismo se ha constituido en uno de los objetos de estudio más abordados por la historiografía latinoamericana predominando, desde un comienzo, las investigaciones que subrayan el lazo directo forjado entre el líder carismático y las masas (Rein y Panella, 2013). Este fenómeno ha sido analizado desde múltiples perspectivas y enfoques teóricos, destacándose aquellos trabajos que han centrado su atención en el tratamiento de las figuras de Juan Perón ${ }^{1}$ y Eva Duarte 2 , así como también aquellos trabajos recientes que han buscado dar cuenta del papel desempeñado por lo que se ha denominado "segunda línea" de liderazgo peronista ${ }^{3}$. Desde el punto de vista ideológico, el peronismo ha sido interpretado como la versión argentina del fascismo italiano, como "totalitarismo", o "populismo". Asimismo, existe un importante acervo bibliográfico que analiza la relación que se estableció entre el entonces coronel Perón y los sindicatos, buscando dar cuenta de la persistencia del peronismo en el movimiento obrero y en la política argentina con posterioridad a la caída de este gobierno en $1955^{5}$, como también toda una línea historiográfica de trabajos que analiza la relación entre este movimiento político y la Iglesia católica, relación caracterizada por un giro que transformó a esta institución de aliada a enemiga, siendo una de las causas que habría precipitado el golpe de Estado de la autodenominada "Revolución Libertadora".

Por último, cabe destacar la existencia de toda una línea historiográfica que analiza la relación entre el peronismo y las universidades reformistas cuyos autores destacan básicamente dos etapas en la misma. La primera de ellas estuvo caracterizada por la "despolitización" de las universidades nacionales a través de la sanción de la ley n. 13.031. Esta normativa no contemplaba el principio de autonomía universitaria y, prácticamente, suprimía la participación estudiantil en el gobierno de las casas de estudios superiores. De acuerdo con lo establecido por las nuevas disposiciones, los rectores serían designados directamente por el Poder Ejecutivo y los decanos por el Consejo Directivo, pero a partir de una terna elevada por el rector. La segunda etapa, en cambio, estuvo signada por la "politización" de la universidad y por el intento de "peronizar" esta institución, que se correspondía además con un intento general por politizar al conjunto del sistema educativo. En este marco, el gobierno instauró la Confederación General Universitaria (CGU) y los llamados

1 Entre estos trabajos biográficos pueden consultarse los de Galasso (2005); Page (1984); Sidicaro (1996).

2 Sobre Eva Duarte de Perón pueden consultarse los trabajos de Chávez (1990); Dujovne Ortiz (1995); Galasso (2012); Navarro (1997) y Zanatta (2011).

3 Véase Rein y Panella $(2013,2017)$.

4 Esta caracterización puede verse en los trabajos de Fayt (2007); Germani (1974) y Laclau (2005), respectivamente.

5 Sobre la relación entre el peronismo y el movimiento obrero, existe una vasta bibliografía. Entre estos estudios, cabe destacarse los de: James (2013); Doyon (2006); Torre (2006, 2012); Murmis y Portantiero (2011) y Del Campo (2012).

6 Véase los trabajos de Bianchi (2001); Caimari (2010) y Zanatta (2013). 
"cursos de formación política", que fueron instrumentados a partir de 1952. El propósito final de los cursos era formar "argentinos dirigentes para salvar nuestro ser nacional, consolidar un orden social justo, afianzar la libertad e independencia del país en sus decisiones". Estos cursos fueron resistidos activamente por los militantes estudiantiles: el ensayo de "peronizar" a la universidad provocó una fuerte reacción negativa de los estudiantes. Por último, cabe señalar que ambas etapas estuvieron atravesadas por un proceso de expulsión masiva tanto de docentes como de estudiantes que no adherían e, incluso, enfrentaron abiertamente al gobierno peronista. En efecto, la "peronización" en las universidades nacionales estuvo principalmente asociada tanto a la forma en la que el peronismo las había "purgado" de los distintos actores que no eran afines a las ideas del nuevo gobierno, como a la creación de la CGU y la imposición de los "cursos de formación política" (Buchbinder, 2005).

En suma, el peronismo es uno de los objetos de estudio que más controversia ha generado - y genera - dentro de la historiografía argentina, y sobre el que menos consenso existe.

La institución que abordaremos en el presente estudio, tiene entre sus características principales el hecho de haber sido la única universidad fundada por el peronismo denominado "clásico"(1946-1955). Asimismo, contaba con características muy diferentes a sus contemporáneas. En principio, se constituyó como el tercer ciclo (ciclo universitario) de un circuito diferenciado de educación técnica dirigido por la Comisión Nacional de Aprendizaje y Orientación Profesional (CNAOP) que dependía, a su vez, directamente del Ministerio de Educación de la Nación. La Universidad Obrera Nacional (UON) solo admitía estudiantes con el título de "técnico", dando prioridad a los egresados del segundo ciclo (ciclo técnico) de las escuelas dependientes de la CNAOP por sobre los egresados de las escuelas industriales de la Nación. Asimismo, poseía una estructura universitaria regionalizada constituida por distintas facultades regionales a lo largo del país, estructura de funcionamiento que tampoco poseía ninguna de las universidades nacionales del periodo. Otra particularidad era que contaba con un sistema de enseñanza particular que combinaba la asistencia obligatoria a clases - las cuales eran dictadas en horario vespertino, permitiendo así la integración al sistema universitario de aquellos trabajadores que realizaban sus tareas laborales durante el día - con la experimentación y la obligación impuesta a los estudiantes de tener que trabajar en la misma rama industrial en la cual cursaban sus estudios. El desarrollo de los cursos se realizaba bajo una modalidad didáctica denominada "clase activa", definida como una clase de "tipo seminario" y "no conferencial", en las que se buscaba que el profesor trabaje junto a los estudiantes y diagramadas en función a la formación de los estudiantes en el marco de la actividad áulica: el objetivo perseguido era que el alumno aprovechara al máximo el tiempo de las cursadas y estudiara en clase, ya que fuera del horario de las mismas no disponía de tiempo para poder hacerlo. La casa de estudios ofreció un total de dieciséis especialidades técnicas a lo largo de este período y el título que eventualmente expediría a sus egresados sería el de "Ingeniero de Fábrica" en la especialización cursada (Koc Muñoz, 2020).

Esta particular institución ha sido abordada por diversos estudios que destacan su creación dentro de un marco más general de análisis que toma por objeto 
a las políticas educativas durante el primer periodo peronista y, dentro de éstas, a la CNAOP. En este sentido, las políticas de ampliación e implementación del sistema de educación técnica oficial a partir de 1944 han sido analizadas desde una perspectiva analítica e histórica en la que pueden rastrearse dos grandes tendencias historiográficas que polarizan este debate.Las mismas polemizan sobre la finalidad subyacente a las propuestas de diversificación del sistema educativo que incorporaban modalidades técnicas. Por un lado la tendencia historiográfica "democratizadora" enfatiza la potencialidad de las políticas educativas mencionadas para impulsar la promoción social de los actores involucrados. La vinculación educación-trabajo y las propuestas de diversificación del sistema responderían, desde esta mirada, a las demandas de los sectores sociales no incluidos hasta el momento ${ }^{7}$. Por otra parte, la tendencia, "discriminadora/desviacionista", sostiene que todo intento de modificación del curriculum clásico humanista es esencialmente discriminador. En consecuencia, la diversificación del sistema educativo aparece aquí como una estrategia política de las élites dirigentes cuya finalidad sería "desviar" a los sectores sociales en ascenso de la universidad y, de esta manera, mantener el monopolio de los saberes socialmente válidos para el ejercicio del poder político ${ }^{8}$.

En líneas generales, el campo de estudios en torno a la CNAOP/UON presenta un alto grado de fragmentación y discontinuidad y los trabajos que lo componen presentan aspectos institucionales muy generales que no dan cuenta de las especificidades del funcionamiento de esta universidad durante su periodo fundacional. En rigor, ninguno de los estudios señalados ha relevado las características que asumió el proceso de "peronización" acontecido al interior de la UON, así como tampoco el proceso de "desperonización” abierto en esta institución a partir del triunfo del golpe de Estado del 16 de septiembre de 1955.

Por su parte, Plotkin (1993) destaca que el gobierno de Perón transformó progresivamente al sistema educativo oficial en un engranaje de su poderosa maquinaria de propaganda, convirtiendo a las escuelas en centros de adoctrinamiento para la juventud. Esta tendencia se hizo particularmente clara durante el periodo en el que Armando Méndez San Martín estuvo a cargo del Ministerio de Educación (1950-1955). Hacia 1950, el gobierno se hallaba embarcado en una dinámica de autoglorificación que requería el monopolio por parte del gobierno del espacio simbólico social y que se expresaría en una marcada "peronización" lisa y llana de los libros de texto en particular y de la educación en general. Tras la muerte de Eva Perón - en 1952 - esta tendencia se hizo más profunda aún. Los homenajes a su memoria se hicieron obligatorios y su autobiografía "La razón de mi vida", fue declarada por ley del Congreso libro de texto obligatorio para todos los niveles de educación. El autor expone de manera detallada cómo se produjo la "socialización

7 A esta línea de trabajo pertenecen los estudios de Balduzzi (1987); Dussel (1990); Mollis (1991); Bernetti y Puiggrós (1993); Dussel y Pineau (1995); Pineau (1997); Somoza Rodríguez (1997); Álvarez de Tomassone (2000); Nápoli (2003); Pronko (2003); Malatesta (2005); y Facio (2014).

8 En esta línea interpretativa se encuentran los trabajos de Kleiner (1964); Wiñar (1970); Tedesco (1980); Novelli (1986); Plotkin (1993); y Koc Muñoz (2014). 
política de la juventud" y la "politización" de la educación a través de los libros de texto "peronistas" en las escuelas primarias, proceso que también ha sido advertido por autores como Rein y Rein (1996) y Corbiére (1999). No obstante, ninguno de estos autores advirtió de qué manera se desarrolló la "peronización" al interior de una institución tan emblemática para el peronismo como lo fue la UON.

Por ello, a través del presente artículo presentaremos el proceso de "peronización" de la UON acontecido durante los años de su funcionamiento bajo el gobierno peronista (1953-1955), entendiendo por “peronización” la imposición — por parte del Estado - de distintos dispositivos formales de adoctrinamiento político tendientes a la apropiación del espacio simbólico y la socialización política de la juventud con el objetivo de consolidar una base de apoyo activa al gobierno peronista lo más amplia posible (Plotkin, 1993). Luego, buscaremos dar cuenta del proceso de "desperonización" - desarrollado luego del derrocamiento de Perón - entendido como la desarticulación de las instituciones y convenciones instauradas por el peronismo en tanto gobierno, movimiento social e imaginario (Ascolani, 2001). A modo de hipótesis, sostenemos que la "peronización" en la UON adquirió características distintas al de las universidades nacionales, debido a que desarrolló toda una serie de mecanismos de adoctrinamiento político no registrado en otras universidades y, en consecuencia, esto condicionó su "desperonización", debido a que la misma estuvo principalmente orientada hacia la erradicación de los mencionados dispositivos.

Este estudio se realizará sobre la base de una estrategia metodológica cualitativa, consistente en la triangulación de dos técnicas metodológicas para la obtención de la información: la investigación documental o "documentación" (Valles, 1999) y la historia oral, entendida como una técnica de búsqueda de información utilizada con un objetivo específico y cuya principal herramienta es la entrevista en profundidad, realizada a fin de registrar aquello que no aparece en los documentos escritos (Folguera, 1994). En suma, se utilizarán distintas fuentes escritas, entre las que se destacan la revista de la UON (en adelante RUON) y las resoluciones de la institución (RESUON), como también la información recogida a través de diversas entrevistas realizadas a ex alumnos de la institución que formaron parte de la UON en el periodo estudiado.

\section{UNA UNIVERSIDAD “PERONISTA”: LOS DISPOSITIVOS DE ADOCTRINAMIENTO POLÍTICO EN LA UNIVERSIDAD OBRERA NACIONAL}

La organización y puesta en funcionamiento de la UON pertenecen al último período del primer peronismo. Si bien la ley mediante la cual se creó esta institución fue sancionada en 1948, recién el 7 de octubre de 1952 el Poder Ejecutivo Nacional reglamentó la forma de organización y funcionamiento de la casa de estudios, abriendo sus puertas finalmente en 1953. Al hacerlo, se prescribió toda una serie de dispositivos tendientes al adoctrinamiento político de los estudiantes en torno a la "Doctrina Nacional Peronista" y de la figura del entonces denominado "Líder de la argentinidad", Juan Domingo Perón. 
El vicerrector de la casa, Pascual Pezzano, consideraba necesario eliminar de los planes de estudio todo conocimiento de carácter accesorio o colateral, como así también asignaturas de carácter cultural o sociológico (Pezzano, 1953). Este tipo de saberes sería impartido por el Instituto de Extensión Cultural y Técnica que fue creado sobre los principios del artículo 37 de la Constitución Nacional de 1949 que establecía que los objetivos del Segundo Plan Quinquenal en materia educativa serían la "formación moral, intelectual y física del pueblo" sobre las premisas de la doctrina nacional peronista, sustrato sobre el que se asentaban los principios ideológicos del peronismo (RESUON n. 33, 1953). En este sentido, la publicación oficial de la UON ${ }^{9}$ destaca que los objetivos señalados por el Segundo Plan Quinquenal adquirían una especial significación, por cuanto los futuros Ingenieros de Fábrica desempeñarían importantes cargos en la dirección de las industrias y economía nacional. Por ello, los directivos de la institución consideraban necesario que los futuros profesionales estuvieran imbuidos con los ideales de la denominada "Nueva Argentina Justicialista". El Instituto de Extensión Cultural y Técnica complementaría los planes de estudios vigentes de las distintas especialidades a través de la difusión del Segundo Plan Quinquenal, la organización de ciclos de conferencias, visitas a establecimientos industriales y laboratorios y la difusión de distintas actividades entre el alumnado (RUON, 1953).

Asimismo, la UON también organizó los "cursos de extensión peronista de la CNAOP" que fueron inaugurados en ocasión del acto de adhesión al día de la lealtad, el 17 de octubre de 1953. Estos cursos tenían por finalidad difundir la doctrina nacional peronista entre el personal de la CNAOP. Si bien no hay un registro documental del contenido de estos cursos, es importante destacar que el director de los mismos consideraba que las ideas filosóficas y sociológicas que dieron origen al naciente movimiento obrero le imprimieron un "rumbo equivocado" y lo alejaron de un supuesto "orden natural" que fue encauzado recién con el advenimiento del justicialismo, el cual era una "creación doctrinal del general Perón" (RUON, 1953). E1 primer ciclo de estos cursos finalizó un año después y egresaron del mismo alrededor de 250 alumnos de la institución. En el acto de clausura, el presidente de la CNAOP, felicitó a sus egresados y declaró que los cursos "tenían como finalidad hacer de cada funcionario un colaborador consciente de los planes del gobierno peronista y un fiel intérprete de su doctrina" (Revista Aprendizaje, 1954).

Otro de los dispositivos de adoctrinamiento político utilizados por esta casa de estudios fue la revista de la UON, la cual fue caracterizada por su secretario de Redacción Fabio Berraute - en su adhesión al Congreso Nacional de la Productividad y Bienestar Social, en 1954 - como "un órgano de difusión doctrinaria"(RUON, 1955, p.14). La publicación reproducía los distintos aspectos de la institución, así como también dedicaba apartados enteros a diversos aspectos como ser: la doctrina peronista, la legislación del trabajo, la cultura nacional, la fundación Eva Perón, la divulgación del

9 La publicación oficial de la UON fue editada por la CNAOP entre septiembre de 1953 y agosto de 1955 . Sólo consta de 13 números, los cuales fueron publicados durante su funcionamiento bajo el gobierno peronista (Koc Muñoz, 2020). 
Segundo Plan Quinquenal, la tercera posición “en la predica y el ejemplo de Perón”, entre otros. También hay publicadas una innumerable cantidad de referencias a la muerte de Eva Perón y homenajes a la "Jefa espiritual de la Nación" y, al menos, un discurso de Perón completo o fragmento discursivo en cada número de la publicación. Esta última sección mencionada, "la tercera posición en la predica y el ejemplo de Perón”, aparece publicada en todas las revistas y es una reconstrucción de la "Doctrina Nacional Peronista" a través de diversos fragmentos discursivos del presidente. Asimismo, la revista en reiteradas publicaciones, destaca a Perón como el creador de la universidad y de una "nueva concepción universitaria" cuyo objetivo era "dotar a nuestro país de sólidos cuadros técnicos altamente capacitados, imbuidos en los nobles ideales de la doctrina nacional peronista" (RUON, 1955, p. 7). En este sentido, el rector de la UON, Cecilio Conditi, afirmaba que "Perón es rector y vicerrector de la Universidad, es 'el que maneja todo; y para no defraudarlo ni traicionarlo es necesario que cada uno cumpla con sus funciones respectivas lo mejor posible"(UON, 1953, p. 108).

Asimismo, otro dispositivo relevado fue la única materia de carácter político-social con la que contaban los programas del primer y segundo año común a todas las carreras, denominada "Sindicalismo Justicialista y Legislación Obrera I y II" respectivamente. Entre las bolillas del primer curso denominada "Proyecciones políticas, jurídicas y económicas del derecho del trabajo", se presentaba a la doctrina justicialista como una de las soluciones propuestas al problema social. En el segundo curso, contenía las bolillas VIII, IX y X, denominadas: "Legislación argentina sobre asociaciones profesionales", "La convención colectiva"y "Legislación argentina sobre convenciones colectivas" respectivamente, mediante las cuales la asignatura cerraba sus contenidos con dos leyes sancionadas durante el gobierno peronista: la ley de la creación de la CNAOP y la ley n. 14.250 sobre convenciones colectivas (RUON, 1955). Según los considerandos de la resolución n. 1 de la UON las materias "Sindicalismo Justicialista", "Legislación del Trabajo" y "Seguridad Industrial", incluidas en todos los planes de estudio de las carreras que se cursaban, tenían como finalidad "el estudio de una nueva realidad social, económica y moral". Asimismo, a través de esta misma resolución, el rector propuso a la CNAOP otorgar el título de "Primer Profesor Honorario" a Perón debido a que era un "paladín de la cultura popular y de la elevación y perfeccionamiento de los trabajadores y como un conductor genial de las masas populares que imparte a diario lecciones continuas con su verbo inflamando, de esta manera, de justicia y dignidad al pueblo argentino" (RESUON n. 1, 1953). Finalmente, Perón fue nombrado bajo este título en 1954 (Revista Aprendizaje, 1954).

Otra de las disposiciones adoptadas por la universidad - en este mismo sentido - fue la resolución n. 22, en la que se destaca que Perón había creado la única casa de estudios con estas características en el mundo y que el presidente era el "libertador de la república, el forjador de su independencia económica", y que Eva Perón - quien era considerada "Jefa espiritual de la Nación" — había sido una de las "más entusiastas propulsoras de esta iniciativa del líder de los argentinos" y que, por lo tanto, fueron los "exponentes y creadores de la nueva conciencia social argentina impregnada con un profundo sentido humanista” (RESUON n.22,1953). Por ello, el rector de la UON, instituía que en todas las dependencias y aulas de la UON serían colocados cuadros con las efigies de Perón y de Eva Perón. Por último, mediante la 
resolución n. 46, el rectorado resolvió denominar "Juan Perón" al aula magna de la UON debido a que "era el resultante del genio y de la inspiración creadora del Líder de los trabajadores argentinos"; además, era "el forjador de la Nueva Argentina, libre, justa y soberana, que constituye un ejemplo para las otras comunidades nacionales, que soportan la dominación de los imperialismos y sufren los grandes flagelos emergentes de un régimen social que se sustenta en la explotación y la miseria de los hombres y mujeres del trabajo"; y también era "el creador de la Doctrina Nacional que ha consolidado la unión del pueblo argentino y que este levanta como estandarte de su fe en un destino mejor para la humanidad" (RESUON n. 46, 1953).

El último de los dispositivos relevados en el presente trabajo, es el Calendario y Plan de Trabajo de los años 1954 y 1955. En ellos, puede observarse una serie de rituales preestablecidos que se desarrollaban al interior de la institución, cuya forma variaba de acuerdo con la conmemoración dispuesta. Entre los mismos, se destacan: cantar el himno nacional, hacer un minuto de silencio en homenaje a Eva Perón, pronunciar un discurso alusivo por parte del personal directivo o docente y un alumno cuya duración no excedería los diez minutos y finalmente escuchar la marcha "Los muchachos peronistas". Estas formas de conmemoración tenían una ritualidad similar, a excepción de los días 26 de julio - día de duelo nacional en homenaje a la "Jefa Espiritual de la Nación, Sra. Eva Perón" - cuya forma preestablecida de conmemoración instituía: "10 un minuto de silencio. $2^{\circ}$ ofrenda floral al pie del busto de la Sra. Eva Perón. $3^{\circ}$ palabras alusivas por el personal directivo o docente y un alumno". Por último, el Calendario y Plan de Trabajo también establecía que, tanto el personal directivo como docente, administrativo y de servicio, debía concurrir de manera obligatoria o justificar posteriormente su inasistencia a los actos de la universidad (RUON, 1954, p. 35-36).

Entre las fechas de conmemoración establecidas en la UON, se encontraba: el día de la constitución justicialista, cumpleaños de la "Jefa Espiritual de la Nación", el día de Duelo Nacional (anteriormente aludido), el cumpleaños de Perón y el día de la Lealtad Popular (17 de octubre). Por último, se había instaurado, el 7 de mayo de 1953 (día del cumpleaños de Eva Perón), a través de la resolución n. 28 de la $\mathrm{UON}^{10}$, que todos los días 26 de cada mes, a las 20:25 hrs., todos los alumnos,

10 La parte que fundamenta esta resolución expresa: "Que por una declaración conjunta de las Cámaras de Diputados y Senadores de la Nación, la señora Eva Perón es Jefa Espiritual de la Nación, y como tal debe reconocérsele; que es necesario que la juventudes que se conforman moral e intelectualmente en las casas de estudio de nuestro país, honren a quien todo lo dio por su pueblo y por su patria y nada exigió en cambio, sino amor y lealtad; que fue la Jefa Espiritual de la Nación, quien más se distinguió y preocupó por lograr que las puertas de nuestras universidades estuviesen permanentemente abiertas a todos y muy especialmente los trabajadores que por su capacidad intelectual y su contracción al estudio mereciera en estar en las aulas; que la Universidad Obrera Nacional y sus Facultades Regionales, constituyen la expresión vívida de ese anhelo de la Jefa Espiritual de la Nación y en consecuencia sus alumnos tienen para con ella mayores obligaciones morales que cualquiera de otros establecimientos educacionales; que, por otra parte, la Jefa Espiritual de la Nación ha sido la verdadera animadora y propulsora que ha convertido en una hermosa realidad la Universidad Obrera Nacional para los trabajadores argentinos" (RESUON n. 28, 1953). 
profesores y demás personal, sin excepciones, guardaría un minuto de silencio "como prueba de respeto y veneración para con la Jefa Espiritual de la Nación. Salvo expresa disposición previa al respecto, lo dispuesto se cumplirá en el lugar de tareas de cada uno"(RESUON n. 28,1953). Todas estas fechas de conmemoración compartían la característica de tener algún tipo de relación con Perón, con Eva Perón o con algún evento relacionado al peronismo, como ser el surgimiento del mismo, o la sanción de la constitución de 1949.

\section{LA “REVOLUCIÓN LIBERTADORA” Y LA “DESPERONIZACIÓN” EN LA UON}

Pocos días después del golpe de septiembre de 1955 que derrocó al gobierno peronista, las universidades nacionales fueron ocupadas por agrupaciones estudiantiles que habían militado en la oposición al peronismo. En la gran mayoría de los casos se impidió a las autoridades nombradas por el gobierno derrocado acceder a las dependencias de las casas de estudios. Durante los últimos días de septiembre y principios de octubre de 1955, las universidades fueron intervenidas y se designaron nuevas autoridades al frente de cada una de ellas. Para el ministro de Educación, Atilio Dell'Oro Maini, las universidades debían reorganizarse sobre la base del respeto a la autonomía. El personal docente de las casas de estudios debía ser declarado en comisión y reemplazado, en su totalidad, a partir de la convocatoria de nuevos concursos de títulos y antecedentes. Una vez constituido el claustro profesoral, las universidades debían sancionar los nuevos estatutos y elegir a las nuevas autoridades (Buchbinder, 2005).

El nuevo gobierno militar otorgó amplias facultades a los interventores para que éstos pudiesen comenzar la reorganización de las casas de estudios. Utilizando dichas atribuciones, procedieron a "desperonizar" las instituciones académicas. De esta manera, tuvo lugar un nuevo proceso de cesantías masivas de profesores, auxiliares docentes y personal administrativo comprometidos de una manera u otra con el "régimen depuesto". Muchos de los entonces cesanteados habían participado activamente del gobierno peronista. El apoyo a la reelección o el respaldo a la concesión del doctorado Honoris Causa a Perón fueron los motivos esgrimidos con mayor frecuencia para justificar la expulsión (Neiburg, 1998). Como había ocurrido en 1946, a los cesanteados se sumó un número importante de docentes que decidieron alejarse, en muestra de solidaridad. Los criterios políticos imperaron también en el masivo llamado a concursos que se implementó durante los años 1956 y 1957. En la incorporación o separación de docentes era, además de sus conocimientos, la "conducta" el factor central a considerar. La "honradez" del profesor pasó a ser una condición prioritaria para evaluar una trayectoria académica y la "moralidad" era un título indispensable para acceder a la cátedra (Buchbinder, 2005).

Las autoridades del gobierno de facto reimplantaron la Ley Avellaneda, pero días más tarde la reemplazaron por un nuevo decreto, el n. 6.403/1955, que puso las bases definitivas para la construcción del conjunto del sistema. Este decreto amplió y fortaleció la autonomía universitaria; otorgó a las casas de estudios un grado de independencia del que no habían gozado durante todo el periodo reformista comprendido entre 1918 y 1943. Concedió a las autoridades universitarias la potestad 
para administrar su patrimonio y darse su estructura y planes de estudios. Les otorgó, además, libertad para organizar sus formas de gobierno y, por supuesto, dictar sus estatutos siempre que asegurasen la "responsabilidad directiva de los representantes del claustro de profesores". El decreto dedicaba todo un capítulo a las formas de designación de los profesores. Allí se explicitaba la limitación impuesta a todos aquellos que "hubiesen realizado actos positivos y ostensibles de solidaridad con la dictadura". La expresión tenía como principales destinatarios a todos los vinculados, de una forma u otra, con el gobierno derrocado en 1955. Progresivamente, también la aprobación de los planes de estudios y la designación de los profesores quedaron en forma definitiva en manos de las mismas autoridades de la universidad. Esta medida constituyó una innovación particularmente relevante, ya que dejó sin efecto el antiguo sistema de presentación de ternas ante el Poder Ejecutivo (Buchbinder, 2005). Por último, cabe señalar que el artículo $29^{\circ}$ del mencionado decreto establecía que en todas las universidades nacionales debía llamarse a concurso de títulos y antecedentes para la designación de profesores titulares en las cátedras de las respectivas facultades.

El proceso de "desperonización”, en la mayoría de las universidades nacionales, estuvo orientado hacia la exclusión de aquellos profesores que -en mayor o menor medida- dieron su apoyo al gobierno peronista a través del concurso de todos los cargos docentes: la "desperonización” era sinónimo de "depuración” (Neiburg, 1998). En este sentido, el caso de la Universidad de Buenos Aires (UBA) resulta paradigmático. El 16 de septiembre de 1955 - al mismo tiempo que se producía el golpe de Estado - la Federación Universitaria de Buenos Aires (FUBA) tomó las instalaciones de la UBA y la administración peronista fue sustituida por el "gobierno de los Centros de Estudiantes". Los dirigentes estudiantiles generaron una situación de fuerza con la intención de influir en la "desperonización" de la casa de estudios. E1 2 de octubre fue designado como interventor José Luis Romero, terminando así con el gobierno estudiantil. En este contexto, la dictadura suspendió en sus cargos a todos los profesores y llamó de inmediato a concurso de títulos y antecedentes para la totalidad de las cátedras. Un mes más tarde, las autoridades establecieron los requisitos que debían cumplir los candidatos que interesados en concursar: "poseer título universitario y exhibir una conducta moral inobjetable" y, "un comportamiento cívico ajeno a toda adhesión a las conductas totalitarias, adversas a la dignidad del hombre libre y a la vigencia de las instituciones republicanas", no siendo admitidos quienes "hayan realizado actos positivos y ostensibles de solidaridad con la dictadura". Asimismo, se constituyeron Comisiones Asesoras "para juzgar la conducta de los candidatos frente a la dictadura depuesta" y se estableció que de cada concurso debería resultar la elección de una terna de individuos de la que, finalmente, el Poder Ejecutivo escogería a uno para ocupar la cátedra. En los concursos, cada candidato debía firmar un documento en el que declaraba no haber mantenido ningún tipo de compromiso con el gobierno depuesto. Pero independientemente de este juramento, las autoridades universitarias se reservaban el derecho de impugnar las candidaturas de algunos individuos tomando como base las acusaciones relativas a su "conducta moral" durante la década anterior. Dos denuncias eran incluidas en todas las impugnaciones: la firma del pedido de reelección de Perón en 1951 y el 
apoyo brindado poco tiempo después por el acusado al otorgamiento del título de Doctor "Honoris Causa" a Perón. Los encargados de realizar estas impugnaciones eran los representantes de la Agrupación de Egresados de la Facultad y del Centro de Estudiantes, destacándose así la preeminencia que tenían los estudiantes en el nuevo gobierno universitario (Neiburg, 1998).

Procesos similares a los acontecidos en la UBA fueron registrados en la Universidad Nacional de La Plata (Pis Diez, 2016), en la Universidad del Litoral (Salomón, 2014) y en el Instituto Tecnológico del Sur, que devino en Universidad Nacional del Sur en el marco de este proceso ${ }^{11}$ (Orbe, 2008).

Por su parte, los estudiantes de la Regional Buenos Aires de la UON regresaron a la casa de estudios el 27 de septiembre de 1955 y, desconociendo a las autoridades de la casa, conformaron la "Junta Provisional de Estudiantes de la Facultad Regional Buenos Aires". Las primeras medidas llevadas adelante por este agrupamiento estudiantil fue realizar la ocupación de las dependencias del establecimiento. Asimismo, solicitaron la autonomía y el cambio de nombre de la institución. Sobre éste, el ex estudiante de la Regional Bahía Blanca recordaba que "todo lo que tenía olor a obrero era 'maldito' en ese momento, y la nuestra era una universidad obrera" (Persichini, 2014). En efecto, luego del golpe de Estado el vocablo "obrero" estaba fuertemente asociado al peronismo. Asimismo, el ex estudiante de la Regional Avellaneda recordaba que el nombre "tenía mucha contra" y que había que modificarlo (López, 2016). El primer nombre que recibió la institución por parte de los estudiantes fue el de "Universidad Técnica Nacional"(La Nación, 28 de septiembre de 1955) aunque, luego de las deliberaciones en diversas asambleas, finalmente se adoptó el de "Universidad Tecnológica Nacional" (Aristeguieta, 1999). Si bien el cambio de nombre fue promulgado por el estudiantado en un primer momento, contó luego con la aprobación explícita tanto del profesorado, como también de las autoridades interventoras de la UON y de la CNAOP (CNAOP II, 1956).

Una vez renombrada la institución, la Junta se puso en contacto con los estudiantes de las facultades del interior del país, para unificar criterios y organizar una entidad a nivel nacional y se resolvió solicitar una entrevista al ministro de Educación, manifestando la preocupación por las reacciones negativas en torno a las distintas creaciones del gobierno peronista y señalando el aspecto demagógico del nombre de la Universidad. Finalmente, los estudiantes de esta Regional asumieron el gobierno de la casa de estudios (Aristeguieta, 1999). A estas acciones se sumaron las de los alumnos

11 El Instituto Tecnológico del Sur fue creado en 1946 por una ley de la Legislatura de la provincia de Buenos Aires, a través de la iniciativa del diputado peronista bahiense Miguel López Francés. E1 Instituto, que comenzó sus actividades académicas en 1948, se estructuró en función de escuelas - de Ciencias Económicas, Química Industrial e Ingeniería Industrial - y no de facultades. A diferencia de las universidades nacionales, el ITS no tenía órganos colegiados. Se había establecido que el rector sería acompañado en sus funciones por un Consejo Académico Superior, integrado por el vicerrector y los directores de las distintas escuelas. En materia académica, los títulos profesionales eran otorgados por la Universidad Nacional de La Plata. Finalmente, el 5 de enero de 1956 fue dictado el decreto-ley 154 por el cual se creaba la Universidad Nacional del Sur (UNS), sobre la base del ITS y con todos los bienes que le estaban afectados (Orbe, 2008). 
de las regionales de Rosario, Avellaneda, Mendoza, Córdoba y La Plata: en Rosario, en una asamblea realizada el 28 de septiembre quedó constituido el Centro de Estudiantes de la Facultad Regional Rosario de la UON (Novelli, 1986). En Avellaneda, cuando los estudiantes volvieron al establecimiento reemplazaron los cuadros con la imagen de Perón por los de San Martín (Lavalle, 2016). Asimismo, se reunieron con el decano y en una conversación de carácter cordial llegaron al acuerdo de llamar a un escribano para hacer - mediante un acta - entrega del patrimonio de la Facultad a los alumnos (Silva, 2016). En Mendoza, el 3 de octubre, se constituyó el "Centro de Estudiantes Libres” de esta Regional e informó que, ante un escribano público, tomó posesión del local, muebles y útiles de la misma. Asimismo, una comisión mixta se hizo cargo del gobierno de la Facultad (La Nación, 4 de octubre de 1955). En Córdoba, la noche del 4 de octubre, los alumnos esta Regional realizaron una asamblea en el salón de actos del establecimiento, resolviendo separar de su cargo al decano sr. Félix Figueroa y entregar el decanato provisionalmente al secretario técnico, ingeniero Adalberto R. Coneh. Luego de la asamblea se labró un acta ante un escribano público, enviándose luego telegramas informando lo ocurrido al Interventor Federal y al ministro de Educación de la Nación (La Nación, 5 de octubre de 1955). Por último, en La Plata, el 5 de octubre los alumnos ocuparon el edificio donde funcionaba esta Facultad Regional. En una asamblea constituida a tal efecto quedó constituida una junta de alumnos que dispuso tomar bajo su control la Facultad Regional, hasta tanto las autoridades respectivas procedieran a la designación del interventor de este ese establecimiento (La Nación, 6 de octubre de 1955).

En este contexto, los estudiantes de la Regional Buenos Aires - que tenían a su cargo del gobierno de la Universidad - dirigieron un comunicado al diario "La Nación" manifestando que retiraban el título de "Primer Profesor Honorario" a Perón y lo hicieron extensivo también al ex gobernador de la provincia de Buenos Aires, Carlos Aloé ${ }^{12}$. Asimismo, también desconocieron la validez de las libretas universitarias por la propaganda peronista contenida en las mismas (La Nación, 16 de octubre de 1955).

Finalmente, el 17 de octubre de 1955 fueron nombradas las autoridades interventoras: Gabriel Meoli como rector, Pedro Berdoy como vicerrector y Luis Lemeillet como secretario general (Ministerio de Educación y Justicia, 1958). Según el diagnóstico realizado por las nuevas autoridades, la institución se había desarrollado sobre un ambiente de "propaganda ideológica y demagógica" pero, no obstante ello, este "ambiente exterior" tuvo poca repercusión en la calidad y nivel de los estudios eminentemente técnicos debido a la conducción del cuerpo docente por parte del vicerrector, el Ing. Pascual Pezzano (CNAOP II, 1956).

Las nuevas autoridades sancionaron una serie de disposiciones destinadas a la "desperonización" de la UON, a través de un conjunto de resoluciones emanadas desde el rectorado. La primera resolución aprobada consistió en la derogación de la resolución n. 1 de la UON, que establecía el pedido por parte del rector a la CNAOP del otorgamiento a Perón del título de "Primer Profesor Honorario".

$12 \mathrm{El}$ gobernador de la provincia de Buenos Aires, Carlos Aloé, fue nombrado profesor honorario de la UON en 1954 (Revista Aprendizaje, 1954). 
Entre los argumentos esgrimidos, se destaca que contenían una "obsecuencia desagradable" y que quien detentaba el mencionado título acalló "la voz de la cultura y del libre pensar" (RESUON n. 119, 1955). Otra de las resoluciones sancionadas en este mismo sentido, fue la derogación de la ya mencionada resolución n. 28, que establecía que todos los 26 de cada mes a las 20 y 25, los alumnos, profesores y demás personal, sin excepciones, debía guardar un minuto de silencio como prueba de "respeto y veneración" a Eva Perón. En la fundamentación se expresa que la participación en la vida pública del país de Eva Perón era demasiado reciente y que sería la historia quien expediría un juicio en forma definitiva (RESUON n. 120, 1955). Asimismo, las autoridades también derogaron la resolución n. 46 por la cual se denominaba al Aula Magna de la Universidad “Juan Perón”. Entre los fundamentos de la derogación de este decreto se subraya que, según las comprobaciones realizadas hasta la fecha por las Comisiones Nacionales Investigadoras, dicho ex funcionario "no puede ser considerado como ejemplo para las juventudes estudiosas" y que "el fallo del Tribunal Superior de Honor del Ejército Argentino ha sido unánime y condenatorio" y, debido a las "gravísimas las comprobaciones efectuadas", el Poder Ejecutivo Nacional "habiendo ratificado y oficializado el fallo del Tribunal Superior mencionado, le retiró el uso de grado y uniforme en la institución armada a la que pertenecía". Frente a tales hechos resultaba "imposible mantener el nombre dispuesto para el aula magna de la Universidad Obrera Nacional” (RESUON n. 121, 1955). Se oficializaba, de este modo, la denominación "Libertad" para el Aula Magna, que había sido dispuesta provisionalmente por la Junta Provisional de alumnos en ejercicio del gobierno de la Universidad. En relación éstos últimos, el rectorado también autorizó la constitución de nuevas organizaciones estudiantiles, siempre que sus estatutos garanticen la "seriedad, corrección de procedimientos y el carácter típicamente estudiantil de las mismas" (RESUON n. 123, 1955).

En relación a los aspectos curriculares se establecía que, hasta tanto se reajusten los planes de estudio y los programas vigentes en todas las especialidades que se cursan en la Universidad, la asignatura de $1^{\circ}$ y $2^{\circ}$ año denominada "Sindicalismo Justicialista y Legislación Obrera", pasaría a denominarse "Sindicalismo y Legislación Obrera" y que, hasta tanto se efectúe el reajuste indicado, no se tomarían exámenes de la citada asignatura, ni las pruebas del tercer término, dándosele por aprobada dicha materia a todos los estudiantes a los efectos de su promoción (RESUON n. 124, 1955). Esta resolución eliminaba la palabra "Justicialista" del nombre de la asignatura en cuestión, debido a que "pretende ser una doctrina especial creada por el régimen depuesto". No obstante la designación de estas asignaturas, la normativa resaltaba que sus programas analíticos contenían muchos "temas aceptables" sobre organización y evolución sindical y legislación del trabajo y que resultaba imposible establecer hasta qué punto los profesores pudieron haber vinculado dichos "temas aceptables" con "hechos y personas del régimen depuesto"(RESUON n. 124,1955).

La "desperonización" alcanzó también al cuerpo docente. Mediante la resolución n. 126, la UON llamó a un concurso general para la provisión de "la totalidad de las horas de clase que se han dictado en el presente curso lectivo y de las que deban crearse para los cursos de 1956". Una de las cláusulas de dicho llamado a concurso establecía que para poder presentarse al mismo, los docentes debían cumplir con el 
requisito de poseer "una conducta cívica ajena a toda adhesión a las doctrinas totalitarias adversas a la dignidad del hombre libre, y de franco apoyo a la vigencia de las instituciones democráticas". También establecía que no serían admitidos al concurso quienes, en el desempeño de un cargo universitario, sindical o de la función pública, hayan realizado "actos positivos y ostensibles de solidaridad con la dictadura que comprometan el concepto de independencia y dignidad de la cátedra"13 (RESUON n. 126, 1955). Asimismo, con relación al plantel docente de la UON, la CNAOP destacaba que los profesores con los que contaba la institución antes de la "Revolución Libertadora" fueron de "calidad despareja", existiendo entre los docentes "figuras de relieve" y otras con "pocos antecedentes para la cátedra", señalando también que los cargos no fueron provistos por concurso, salvo algunas excepciones durante el primer año de funcionamiento. Frente a esta circunstancia, los interventores de la UON solicitaron y obtuvieron autorización de la CNAOP para efectuar un concurso general de títulos y antecedentes con el objeto de cubrir todas las cátedras con los profesores que surgieran como los más capaces por medio de dicho procedimiento. El conjunto de las asignaturas fue dividido en siete grupos: matemáticas, física, química, legislación, estabilidad de las construcciones, mecánica y electricidad y se impuso como condición obligatoria para todos los aspirantes la de poseer título profesional universitario y una antigüedad en el ejercicio de la profesión mayor de tres años. El concurso general se realizó bajo las disposiciones del decreto-ley n. 6.403/1955 y, donde no fue posible aplicar las normas literalmente, se procuró sustituirlas por otras que reflejaran el mismo espíritu de aquéllas. Participaron en calidad de jurados "prestigiosos profesionales", muchos de los cuales constituían figuras de - a juicio de la CNAOP - "primerísima categoría" en el campo de la ciencia y de la técnica argentinas. El resultado final de estos concursos fue la consolidación de un cuerpo de profesores de "primerísima línea" y de "condiciones sobresalientes" para las nueve facultades regionales, que en la mayoría de los casos también pertenecían al cuerpo docente de otras universidades nacionales (CNAOP II, 1956). Asimismo, el prestigioso profesor de la UON y la UBA Manuel Sadosky, resaltaba que los concursos "contribuyeron a confirmar la jerarquía universitaria de los cursos que se dictan" (E1 Laborista, 25 de julio de 1956). Cabe destacar que, a lo largo del presente estudio, no se registraron impugnaciones a los docentes que se presentaron a los concursos, tal como ocurría en otros establecimientos universitarios.

Por último, una vez sancionado a nivel nacional el decreto-ley n. $4 \cdot 161^{14}$, el 14 de marzo de 1956, las autoridades de la UON dispusieron que en la institución quedaba "totalmente prohibido el uso de cualquier designación y emblema que tenga

13 Esta disposición se mantuvo en los llamados a concurso de los años 1956 y 1957.

14 Mediante del decreto-ley n. 4.161, las autoridades nacionales establecieron la prohibición absoluta de utilizar y difundir imágenes, símbolos, signos, expresiones significativas, doctrinas, artículos y obras artísticas que fueran representativas del peronismo, e incluía una lista de vocablos proscritos, tales como "peronismo", "peronista", "justicialismo", "justicialista”, "tercera posición”, la Marcha peronista y los discursos del derrocado presidente Perón y de Eva Perón, así como "el nombre propio del presidente depuesto", "o el de sus parientes". 
relación con el régimen de depuesto" y que "esta resolución es aplicable también a los casos en que deban mencionarse las materias cuya denominación fue cambiada, aun cuando se refieran a los años 1953 y 1954"(RESUON n. 146, 1956). En efecto, no solo fue eliminada la palabra "Justicialista" de la denominación de las asignaturas, sino que, con la nueva disposición, también estaba prohibido expresar el nombre de las mismas bajo su denominación original. Se buscaba, de esta manera, borrar cualquier vestigio del "régimen depuesto" de la UON.

Por su parte, los interventores de la CNAOP consideraban que la UON - a poco de ser inaugurada - comenzó a utilizarse como un instrumento para fines "demagógicos" instados por la propia denominación y por el artículo 10 de la ley n. 13.229/1948 que expresaba que la institución buscaba "la formación integral de profesionales de origen obrero". Asimismo, sostenían que la Universidad, durante el periodo peronista, se caracterizaba por la "índole técnica de los estudios que se realizaban en ella", pero debió desenvolverse permanentemente en un "clima político", y prueba de ello es el análisis que se deriva del "contenido de los trece números de la revista de la UON" (CNAOP II, 1956, p. 6). También destacaban que, tanto el calendario de actividades como los actos públicos y la difusión de la marcha peronista antes de clases fueron los únicos aspectos exteriores que trascendieron y, quienes no estaban vinculados con la Universidad, no conocían el contenido serio y profundo de los estudios técnicos que se impartían. Por lo tanto, la CNAOP consideraba que el nombre de la institución debía ser cambiado, ya que era una "denominación impuesta por las razones demagógicas que caracterizaron muchas de las creaciones del régimen depuesto y quizá la única que el gobierno de la Revolución Libertadora no ha eliminado del léxico oficial" (CNAOP II, 1956, p. 17). Por último, este organismo oficial consideraba que el aditamento "de fábrica" al título que establecía la ley n. 13.229 era "una muestra más del espíritu revanchista" con que fue creada la UON, a través del cual se buscaba contraponer al "ingeniero de overol" con el "ingeniero de cuello duro" y debía ser eliminado (CNAOP VI, 1956, p. 15).

\section{A MODO DE CIERRE}

Los estudios que se han especializado en la relación entre universidad y peronismo no han tomado en cuenta lo acontecido en la UON, limitando sus análisis a las universidades de raigambre reformista. Asimismo, han centrado principalmente su atención en la "peronización" como forma en la que el peronismo había "purgado" a la universidad de los distintos actores que no eran afines a las ideas del nuevo gobierno, dejando prácticamente de lado todo lo referido a las formas de "adoctrinamiento político" llevadas adelante por el gobierno a partir de 1952. En consecuencia, la "desperonización" de las universidades estuvo principalmente asociada al proceso inverso, es decir, al proceso de "depuración” de la universidad de aquellos actores que tuvieron algún tipo de participación o manifestación en favor del recientemente "gobierno depuesto" de Perón.

En este sentido, el presente estudio relevó un proceso de "peronización" diferente: en la UON se desplegó toda una serie de dispositivos tendientes al adoctrinamiento político de los estudiantes que no ha sido registrado en las universidades 
nacionales. Creemos que ello se debió básicamente a tres aspectos: en principio, la UON -a diferencia del resto de las universidades-, dependía de la CNAOP y, a su vez, directamente del Ministerio de Educación, razón por la cual la institución reflejaba de manera más inmediata aquello que acontecía en los establecimientos dependientes de este organismo público. En segundo lugar, fue la única universidad creada por el peronismo en este periodo, lo cual le confirió una mayor capacidad de imponer los dispositivos políticos que considerara convenientes para su funcionamiento. Por último, y relacionado con el punto anterior, la UON no tenía una tradición política previa al peronismo como si tenían las restantes universidades y, por lo tanto, esta casa de estudios no podía ser "depurada" de docentes y estudiantes que no fueran ideológicamente afines al peronismo.

Con el devenir de la "Revolución Libertadora", los estudiantes de la Facultad Regional Buenos Aires, desconocieron a las autoridades de la casa de estudio y conformaron la Junta General Provisional de Estudiantes, que ejerció el gobierno de la universidad durante 20 días, desarrollándose así un proceso muy similar al que acontecía en las otras universidades del país. En este sentido, las primeras medidas tomadas por el estudiantado buscaron la "desperonización" de la UON y consistieron en: cambiar el nombre de la institución al de "Universidad Tecnológica Nacional"; derogar el título de Primer Profesor Honorario otorgado a Perón, haciéndolo de manera extensiva al ex gobernador de la provincia de Buenos Aires, Carlos Aloé; desconocer la validez de las libretas estudiantiles de la UON, por contener propaganda política del "anterior régimen" y cambiar el nombre del aula magna de la universidad — que tenía la denominación del recientemente depuesto presidente - por el de "Libertad". Una vez designadas las autoridades interventoras de la UON, éstas oficializaron las medidas tomadas por los estudiantes de la Junta Provisional añadiendo algunas otras medidas tendientes a borrar todo vestigio del gobierno peronista dentro de la institución. Asimismo, mediante la resolución n. 126, convocaron a concurso de todas las horas cátedra de la universidad con la prohibición de presentarse a docentes que hayan realizado "actos positivos y ostensibles de solidaridad con la dictadura que comprometan el concepto de independencia y dignidad de la cátedra". Sin embargo, estos concursos no tenían un carácter "depurador" tal como ocurría en el resto de las universidades, sino que estuvieron orientados a la búsqueda de la conformación de un cuerpo docente de "primerísima línea” y de la "jerarquización" de esta Universidad: lejos de buscar la separación de algunos docentes afines al "régimen depuesto", la UON amplió su plantel docente sobre la base de la excelencia académica, debido a que necesitaba incorporar nuevos profesores para los nuevos cursos de cuarto año. El proceso de "desperonización" de la UON se extendió entre el 27 de septiembre de 1955 y la sanción de la resolución que prohibía el uso de cualquier designación o emblema que tenga relación con "el régimen de depuesto", el 14 de marzo de 1956. Durante el mismo, los esfuerzos tanto de los estudiantes como de las autoridades interventoras estuvieron centrados en la desarticulación de todo el aparato de adoctrinamiento político montado por el peronismo.

En efecto, el proceso de "desperonización" desarrollado en la UON adquirió características particulares distintas al proceso que se estaba desarrollando en otras 
universidades debido a que respondió a un proceso de "peronización" también distinto, centrado principalmente en la imposición de dispositivos tendientes al adoctrinamiento político de sus estudiantes.

Esta particularidad tampoco ha sido relevada por la bibliografía especializada en la historia de la educación argentina la cual, si bien ha dado cuenta del proceso de creación de la CNAOP y de la UON, no ha centrado su atención sobre el despliegue de los diversos mecanismos de adoctrinamiento al interior de esta última institución, ni del subsiguiente proceso de "desperonización" iniciado a partir de la caída del gobierno peronista, en 1955. En consecuencia, se ha centrado principalmente en debatir - en términos generales - qué lugar ocupó la política de ampliación e implementación del sistema de educación técnica oficial durante el primer y segundo mandato constitucional de Perón en la historia educativa argentina, y si dicha política contribuyó a la "democratización" del sistema educativo o la "segmentación" del mismo. Por último, los trabajos de autores como Plotkin, Rein y Rein o Corbiére, han focalizado su atención en la "peronización" de los libros de texto de niveles educativos no universitarios, no haciendo referencia alguna al proceso de "peronización" acontecido en las universidades reformistas, como tampoco a una institución tan emblemática para el peronismo como lo fue la UON.

\section{REFERENCIAS}

ÁLVAREZ DE TOMASSONE, D. Universidad Obrera Nacional-Universidad Tecnológica Nacional: la génesis de una universidad (1948-1962). Buenos Aires: Edutecne, 2000.

ARGENTINA. Ley n. 13.229. Capítulo II. Boletín Oficial, Buenos Aires, 1948 ARGENTINA. Ley n. 14.250. Capítulo I. Boletín Oficial, Buenos Aires, 1953. ARGENTINA. Decreto-Ley n. 6.403. Capítulos I, II y III. Boletín Oficial, 1955. ARGENTINA. Decreto-Ley n. 4.161. Capítulo 1. Boletín Oficial, Buenos Aires, 1956. ARISTEGUIETA, F. U.T. N. Mi colaboración. Buenos Aires: Dunken, 1999.

ASCOLANI, A. La fuerza ¿¿derecho de las bestias o de la razón? Ciudadanía restringida y educación en Argentina (1955-1958). Anuario de Historia de la Educación, Buenos Aires, n. 3, p. 113-137, 2001.

BALDUZZI, J. Peronismo, saber y poder. In: PUIGGRÓS, A. (dir.). Hacia una pedagogía de la imaginación para América Latina. Buenos Aires: Contrapunto, 1987. p. 169-201.

BERNETTI,J.; PUIGGRÓS, A. Peronismo: cultura política y educación (1945-1955). Buenos Aires: Galerna, 1993.

BIANCHI, S. Catolicismo y peronismo. Religión y política en la Argentina (19431955). Tandil: Instituto de Estudios Históricos-Sociales, 2001.

BUCHBINDER, P. Historia de las universidades argentinas. Buenos Aires: Sudamericana, 2005. 
CAIMARI, L. Perón y la Iglesia Católica: religión, Estado y sociedad en la Argentina (1943-1955). Buenos Aires: Emecé, 2010.

CHÁVEZ, F. Eva Perón sin mitos. Buenos Aires: Fraterna, 1990.

CNAOP II - Comisión Nacional de Aprendizaje y Orientación Profesional. Ministerio de Justicia y Educación. Una institución al servicio del progreso industrial de la Nación. Buenos Aires: Biblioteca del Congreso de la Nación, 1956.

CNAOP VI - Comisión Nacional de Aprendizaje y Orientación Profesional. Ministerio de Justicia y Educación. Dictamen sobre la Universidad Tecnológica Nacional. Su defensa frente a proyectos de disolución y desjerarquización. Buenos Aires: Biblioteca del Congreso de la Nación, 1956.

CORBIÉRE, E. Mamá me mima, Evita me ama. La educación argentina en la encrucijada. Buenos Aires: Sudamericana, 1999.

DEL CAMPO, H. Sindicalismo y peronismo. Los comienzos de un vínculo perdurable. Buenos Aires: Siglo XXI, 2012.

DOYON, L. Perón y los trabajadores. Los orígenes del sindicalismo peronista, 1943-1955. Buenos Aires: Siglo XXI, 2006.

DUJOVNE ORTIZ, A. Eva Perón. La biografía. Buenos Aires: Aguilar, 1995.

DUSSEL, I. El movimiento estudiantil en el surgimiento de la Universidad Tecnológica Nacional: los casos de la UBA y la UTN (1945-1966). Informe final de investigación. Buenos Aires: FLACSO, 1990.

DUSSEL, I.; PINEAU, P. De cuando la clase obrera entró al paraíso: la educación técnica estatal en el primer peronismo. In: PUIGGRÓS, A. (dir.). Historia de la educación en Argentina. Discursos pedagógicos e imaginario social durante el primer peronismo (1945-1955). Buenos Aires: Galerna, 1995. t. VI, p. 107-173.

EL LABORISTA.En defensa de la Universidad Tecnológica Nacional. Buenos Aires: Biblioteca Nacional Mariano Moreno, 25 jul. 1956.

FACIO, M. "La Cenicienta de las Universidades" de la Universidad Obrera Nacional a la Universidad Tecnológica Nacional. El caso de la Facultad Regional Avellaneda (1943-1963). 2014. 168 f. Tesis (Maestría en Ciencias Sociales del Trabajo) Universidade de Buenos Aires, Buenos Aires, 2014.

FAYT, C. La naturaleza del peronismo. Buenos Aires: ERREPAR, 2007.

FOLGUERA, P. Cómo se hace historia oral. Madrid: Eudema, 1994.

GALASSO, N. Perón. Buenos Aires: Colihue, 2005.

GALASSO, N. La compañera Evita. Buenos Aires: Colihue, 2012.

GERMANI, G. Política y sociedad en una época de transición. De la sociedad tradicional a la sociedad de masas. Buenos Aires: Paidós, 1974.

JAMES, D. Resistencia e integración. El peronismo y la clase trabajadora argentina 1946-1976. Buenos Aires: Siglo XXI, 2013.

KLEINER, B. Veinte años de movimiento estudiantil reformista (1943-1963). Buenos Aires: Platina, 1964. 
KOC MUÑOZ, A. "Más que hombres sabios necesitamos hombres buenos”. La expansión de la educación técnica durante el Primer Peronismo (1944-1955). La Comisión Nacional de Aprendizaje y Orientación Profesional y la Universidad Obrera Nacional. 2014. 102 f. Tesis (Grado) - Facultad de Humanidades y Ciencias de la Educación, Universidad Nacional de La Plata, La Plata, 2014.

KOC MUÑOZ, A. Una Universidad “de verdad”. Organización, funcionamiento y "reformización" de la Universidad Obrera Nacional (1948-1959). 2020. Tesis (Doctoral en Ciencias de la Educación inédita) - Universidad Nacional de La Plata, La Plata, 2020.

LA NACIÓN. En la Universidad Obrera Nacional. Buenos Aires: Hemeroteca de la Universidad Nacional de La Plata, 28 sep. 1955.

LA NACIÓN. En la Facultad Regional de la Universidad Obrera. Buenos Aires: Hemeroteca de la Universidad Nacional de La Plata, 4 oct. 1955.

LA NACIÓN.Alumnos tomaron posesión de la Universidad Obrera. Buenos Aires: Hemeroteca de la Universidad Nacional de La Plata, 5 oct. 1955.

LA NACIÓN. Ocuparon los alumnos la Universidad Obrera. Buenos Aires: Hemeroteca de la Universidad Nacional de La Plata, 6 oct. 1955.

LA NACIÓN. Universidad Tecnológica Nacional. Buenos Aires: Hemeroteca de la Universidad Nacional de La Plata, 16 oct. 1955.

LACLAU, E. La razón populista. Buenos Aires: FCE, 2005.

LAVALLE, C. Entrevista. Entrevista cedida a Álvaro Sebastián Koc Muñoz. Quilmes: 11 ago. 2016.

LÓPEZ, J. Entrevista. Entrevista cedida a Álvaro Sebastián Koc Muñoz.Avellaneda: 19 jul. 2016.

MALATESTA, A. El surgimiento de la Universidad Obrera Nacional en la Argentina de fines de la década de 1940. Revista Diálogos Pedagógicos, Córdoba, año III, n. 6, p. 22-33, 2005.

MINISTERIO DE EDUCACIÓN Y JUSTICIA. Memoria. Reseña de la labor cumplida desde el 23 de septiembre de 1955 hasta el 31 de diciembre de 1957 por los distintos organismos y la que se proyecta realizar hasta el 30 de abril de 1958. Buenos Aires: Centro Nacional de Información y Documentación Educativa CENIDE, 1958.

MOLLIS, M. La historia de la Universidad Tecnológica Nacional: una universidad para hombres y mujeres que trabajan. Revista Realidad Económica, Buenos Aires, n. 99, p. 91-108, 1991.

MURMIS, M.; PORTANTIERO, J. Estudios sobre los orígenes del peronismo. Buenos Aires: Siglo XXI, 2011.

NÁPOLI, P. Política educativa y organización académica en el período fundacional de la Universidad Tecnológica Nacional (1948-1962). Buenos Aires: Edutecne, 2003. NAVARRO, M. Evita. Buenos Aires: Planeta, 1997.

NEIBURG, F. Los intelectuales y la invención del peronismo. Buenos Aires: Alianza, 1998. 
NOVELLI, N. Movimientos estudiantiles en la Universidad Tecnológica Nacional (1953-1958). 1986. 41 f. Tesis (Licenciatura en Ciencias de la Educación) — Facultad de Derecho y Ciencias Sociales de la Universidad Católica Argentina, Rosario, 1986. ORBE, P. Autonomía, reestructuración institucional y desperonización: el impacto de la Revolución Libertadora en la comunidad universitaria bahiense (1955-1957). Revista Sociohistórica, La Plata, n. 23-24, p. 137-162, 2008.

PAGE, J. Perón. Buenos Aires: Vergara, 1984.

PERSICHINI, A. Sesenta años de historia. Pasado, presente y futuro. Entrevista. Buenos Aires: Faculta Regional Bahía Blanca, 2014.

PEZZANO, P. [Manuscritos inéditos]. Buenos Aires: Decanato de la Facultad Regional Buenos Aires de la Universidad Tecnológica Nacional, 1953.

PINEAU, P. De zoológicos y carnavales: las interpretaciones sobre la Universidad Obrera Nacional. In: CUCUZZA, H. (dir.). Estudios de Historia de la Educación durante el Primer Peronismo (1943-1955). Buenos Aires: Los Libros del Riel, 1997. p. 205-227.

PIS DIEZ, N. El movimiento estudiantil de la Universidad Nacional de La Plata ante la "Revolución Libertadora": actores, transformaciones y conflictos entre septiembre de 1955 y mayo de 1956. Revista Sociohistórica, La Plata, n. 37, p. 1-15, 2016.

PLOTKIN, M. Mañana es San Perón. Propaganda, rituales políticos y educación en el régimen peronista (1946-1955). Buenos Aires: Ariel-Historia Argentina, 1993. PRONKO, M. Las Universidades del trabajo en Argentina y Brasil. Una historia de las propuestas de su creación. Entre el mito y el olvido. Montevideo: CINTEFOR/ OIT, 2003.

REIN, M.; REIN, R. Populismo y educación: el caso peronista. Revista del Instituto de Investigaciones en Ciencias de la Educación, Buenos Aires, año 5, n. 8, p. 50-57, 1996. REIN, R.; PANELLA, C. La segunda línea. Liderazgo peronista 1945-1955. Tres de Febrero: EDUNTREF, 2013.

REIN, R.; PANELLA, C. Los indispensables. Dirigentes de la segunda línea peronista. San Martin: UNSAM edita, 2017.

RESOLUCIONES DE LA UON. Buenos Aires: Rectorado de la Universidad Tecnológica Nacional, n. 1, 22, 28, 33 y 46, 1953.

RESOLUCIONES DE LA UON. Buenos Aires: Rectorado de la Universidad Tecnológica Nacional, n. 119, 120, 121, 123, 124 y 125, 1955.

RESOLUCIONES DE LA UON. Buenos Aires. Rectorado de la Universidad Tecnológica Nacional, n. 146, 1956.

REVISTA APRENDIZAJE. Comisión Nacional de Aprendizaje y Orientación Profesional, año I, n. 6, 1952, 1952. Buenos Aires: Biblioteca Nacional Mariano Moreno, 1952.

REVISTA APRENDIZAJE. Comisión Nacional de Aprendizaje y Orientación Profesional, año III, n. 16 y 17, 1954. Buenos Aires: Biblioteca Nacional Mariano Moreno, 1954. 
REVISTA DE LA UON. Comisión Nacional de Aprendizaje y Orientación Profesional, año I, n. 1 y 3, 1953. Buenos Aires: Biblioteca del Congreso Nacional, 1953.

REVISTA DE LA UON. Comisión Nacional de Aprendizaje y Orientación Profesional, año II, n. 6, 1954. Buenos Aires: Biblioteca del Congreso Nacional, 1954. REVISTA DE LAUON. Comisión Nacional de Aprendizaje y Orientación Profesional, año III, n. 11 y 12, 1955. Buenos Aires: Biblioteca del Congreso Nacional, 1955.

SALOMÓN, P. Intervención, desperonización y elencos de gobierno. La universidad nacional del litoral entre 1955-1958. Revista Papeles del Centro de Investigaciones, Santa Fe, n. 15, p. 15-33, 2014.

SILVA, A. Entrevista. Avellaneda: 19 jul. 2016.

SIDICARO, R. Los nombres del poder: Juan Domingo Perón. Buenos Aires: Fondo de Cultura Económica, 1996.

SOMOZA RODRÍGUEZ, M. Interpretaciones sobre el proyecto educativo del Primer Peronismo. De "agencia de adoctrinamiento" a "instancia procesadora de demandas". Anuario de Historia de la Educación, Buenos Aires, n. 1, p. 163-184, 1997.

TEDESCO, J. La educación argentina (1930-1955). Buenos Aires: CEAL, 1980.

TORRE, J.La vieja guardia sindical. Sobre los orígenes del peronismo. Tres de Febrero: EDUNTREF, 2006.

TORRE, J. Ensayos sobre movimiento obrero y peronismo. Buenos Aires: Siglo XXI, 2012.

UON - Universidad Obrera Nacional. Libro de actas de las reuniones de decanos y secretarios técnicos. Buenos Aires: Consejo Superior del Rectorado de la Universidad Tecnológica Nacional, 1953.

VALLES, M. Técnicas cualitativas de investigación social. Reflexión metodológica y práctica profesional. Madrid: Síntesis, 1999.

WIÑAR, D. Poder político y educación. El peronismo y la CNAOP. Buenos Aires: Centro de Investigaciones en Ciencias de la Educación del ITDT, 1970.

ZANATTA, L. Eva Perón. Una biografía política. Buenos Aires. Sudamericana, 2011.

ZANATTA, L. Perón y el mito de la Nación católica. Iglesia y Ejército en los orígenes del peronismo (1943-1946). Tres de Febrero: EDUNTREF, 2013.

\section{SOBRE O AUTOR}

Álvaro Sebastián Koc Muñoz es doctorando en Ciencias de la Educación por la Universidad Nacional de La Plata (Argentina). Asimismo, es becario interno doctoral del Consejo Nacional de Investigaciones Científicas y Técnicas (CONICET) con lugar de trabajo en el Instituto de Investigaciones en Humanidades y Ciencias Sociales (IdIHCS) de la UNLP (Argentina). E-mail: sebastiankoc84@gmail.com 
Conflictos de interés: $\mathrm{El}$ autor declara no haber ningún interés comercial o asociativo que represente conflicto de interés no que se refiere al manuscrito.

Financiamiento: El estudio fue financiado por el Consejo Nacional de Investigaciones Científicas y Técnicas de Argentina (CONICET).

Recibido el 6 de junio de 2020 Aprobado el 26 de noviembre de 2020 